\title{
Effect of Pressure Support Ventilation on Carboxyhemoglobin Toxicokinetic after Acute Carbon Monoxide Intoxication: a Swine Model
}

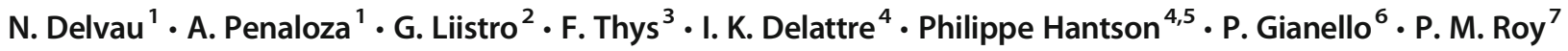

Received: 1 September 2017 / Revised: 17 January 2018 / Accepted: 19 January 2018 / Published online: 21 February 2018

(C) American College of Medical Toxicology 2018

\begin{abstract}
Introduction In an experimental study on carbon monoxide (CO) exposure in swine, we aimed to compare the influence of oxygen therapy using a non-rebreathing mask (NRM) to continuous positive airway pressure (CPAP) and two pressure support ventilation (PSV) devices on the decrease of the terminal elimination half-life of carboxyhemoglobin $\left(\mathrm{COHb} \mathrm{t}_{1 / 2}\right)$. This was the primary outcome.

Methods Eight spontaneously breathing pigs were sedated by propofol and exposed to $940 \mathrm{ppm}$ CO several times $(n=25)$ to obtain $\mathrm{COHb}$ levels of $30 \%$. CPAPb (high flow open system, CPAP Boussignac ${ }^{\circledR}\left[7.5 \mathrm{cmH}_{2} \mathrm{O}\right]$ ), PSV-Vy (open system, Vylife Boussignac ${ }^{\circledR}$ ), and PSV-Leg (closed system, Legendair ${ }^{\circledR}$ [inspiratory/expiratory airway pressure $12 / 4 \mathrm{cmH}_{2} \mathrm{O}$ ]) devices were used in a randomized order and compared to $\mathrm{NRM}\left(\mathrm{O}_{2}\right.$ at $\left.151 \mathrm{~min}^{-1}\right)$ and atmospheric air (AA). The primary outcome was $\mathrm{COHb}$ $\mathrm{t}_{1 / 2}$. Multiple comparisons were performed using Dunn's tests.

Results Median $\mathrm{FiO}_{2}$ and minute ventilation were significantly higher in the PSV-Leg group than the NRM group $(p<0.05)$. Median $\mathrm{COHb}_{1 / 2}$ was 251, 85, 82, 93, and 58 min for AA, NRM, CPAPb, PSV-Vy, and PSV-Leg, respectively. All the interventions were superior to AA in terms of CO elimination $(p<0.001)$, but there was no statistically significant difference between CPAP or PSV and NRM. There was only a trend between PSV-Leg and NRM $(p=0.18)$. The median AUCs for ln $(\mathrm{COHb}) \times$ time $(\mathrm{h})$ were 170, 79, 83, 100, and 64 for AA, NRM, CPAPb, PSV-Vy, and PSV-Leg respectively, with a statistically significant difference only between AA and PSV-Leg $(p=0.002)$.

Conclusion In conclusion, in our study on CO intoxication in swine, the use of the closed PSV-Leg system led to the shortest $\mathrm{COHb}_{1 / 2}$. These results suggest that PSV-Leg can be more efficient than NRM in eliminating CO and support the design of a clinical study to assess this hypothesis.
\end{abstract}

Keywords Carbon monoxide - Swine $\cdot$ Positive pressure ventilation $\cdot$ Continuous positive airway pressure (CPAP) . Toxicokinetic $\cdot$ Carboxyhemoglobin $(\mathrm{COHb}) \cdot$ Oxygen therapy

This work has been partly presented as a poster at the 37th ISICEM

Congress in Brussels, Belgium, March 21-24, 2017 and the

corresponding abstract was published in Critical Care 2017, 21(Suppl

1):56.

Electronic supplementary material The online version of this article (https://doi.org/10.1007/s13181-018-0654-8) contains supplementary material, which is available to authorized users.

Philippe Hantson

philippe.hantson@uclouvain.be

1 Department of Emergency Medicine, Cliniques universitaires Saint-Luc, Université Catholique de Louvain,

1200 Brussels, Belgium

2 Department of Pneumology, Cliniques universitaires Saint-Luc, Université Catholique de Louvain, 1200 Brussels, Belgium

3 Emergency Department, Grand Hôpital de Charleroi, 6000 Charleroi, Belgium
4 Louvain center for Toxicology and Applied Pharmacology (LTAP), Université Catholique de Louvain, 1200 Brussels, Belgium

5 Department of Intensive Care, Cliniques universitaires Saint-Luc, Université Catholique de Louvain, Avenue Hippocrate 10, 1200 Brussels, Belgium

6 Department of Health Sciences, Institute for Experimental and Clinical, Experimental Surgery and Transplantation (CHEX), Université Catholique de Louvain, 1200 Brussels, Belgium

7 Department of Emergency Medicine, Centre Hospitalier Universitaire, 49033 Angers Cedex 01, France 


\section{Introduction}

Carbon monoxide ( $\mathrm{CO})$ is one of the most frequent causes of toxic deaths in the world [1]. The main objective of oxygen therapy for $\mathrm{CO}$ poisoning is to increase the $\mathrm{CO}$ elimination rate, i.e., to decrease the elimination half-life of carboxyhemoglobin $\left(\mathrm{COHb} \mathrm{t}_{1 / 2}\right)$. The final objective of this therapeutic approach is to prevent delayed neurological sequelae.

The mode of oxygen administration strongly influences its efficacy: $\mathrm{COHb} \mathrm{t}_{1 / 2}$ ranges from $320 \mathrm{~min}$ at atmospheric room air (AA) to $71 \mathrm{~min}$ with normobaric oxygen therapy coupled to a non-rebreather mask (NRM) at $151 \mathrm{~min}^{-1}$ and to $21 \mathrm{~min}$ with hyperbaric oxygen (HBO) therapy at a pressure of 1.5 to $3.0 \mathrm{~atm}$ absolute (ATA) $[2,3]$.

Nevertheless, the clinical benefit of HBO therapy for the prevention of neurological sequelae is still under debate. HBO therapy could even expose the victims to deleterious effects [4-6]. While oxygen seems to be the natural antidote for CO poisoning, there is some concern regarding the role of massive oxygen therapy on free-radical production, leading to further cellular damage $[4,6]$. Moreover, HBO therapy is not uniformly available in all areas at all times, which leads to significant delays in initiating therapy [7]. This led us to investigate other convenient ways to improve $\mathrm{CO}$ elimination. Continuous positive airway pressure (CPAP) with high flow oxygen device and pressure support ventilation (PSV) may positively influence fraction of inspired oxygen $\left(\mathrm{FiO}_{2}\right)$ and minute ventilation and may be candidates for $\mathrm{CO}$ intoxication treatment [8]. Our hypothesis was that these ventilation techniques, which are more convenient and more widely available than HBO, could be more efficient in eliminating $\mathrm{CO}$ than NRM. However, as these techniques had not been previously evaluated in this context, a preliminary assessment was required in order to ensure that our hypothesis was plausible and could be safely tested in a clinical setting, find the most promising ventilation support, and estimate the number of patients required for a clinical study. We therefore performed a pilot experimental study on swine in which we compared the effect of CPAP and two PSV devices to NRM and atmospheric air (as a control without treatment) on $\mathrm{COHb} \mathrm{t}_{1 / 2}$.

\section{Materials and Methods}

A prospective exploratory randomized trial on swine was conducted using eight male Landrace pigs (77 kg, [72-88]). This animal experimental study was approved by the Université Catholique de Louvain's ethics committee for animal experimentation (UCL, Brussels, Belgium) (ref 2013/UCL/MD/001 and ref 2015/UCL/MD/28). Formal approval was obtained for the use of the photographs taken during the experiments.
Intubation was performed on the animals using a cuffed endotracheal tube ( 7.5 to 8.0$) 15$ to 20 min after they had been pre-medicated with intramuscular injections of tiletamine/ zolazepan (Zoletil® 100, Virbac@ $\left(6 \mathrm{mg} \mathrm{kg}^{-1}\right)$ and Xylazin (Rompun ${ }^{\circledR} 2 \%$, Bayer@) $\left.\left(2 \mathrm{mg} \mathrm{kg}^{-1}\right)\right)$. The pigs were sedated with a continuous intravenous administration of propofol (1.5 to $2.3 \mathrm{mg} \mathrm{kg}^{-1}$ ) in order to maintain spontaneous breathing throughout the study. Intubation was required to avoid obstructive apneic episodes during sedation and to record minute ventilation and end-tidal $\mathrm{CO}_{2}$ levels during the experiment. In order to try to reproduce non-invasive positive pressure ventilation (NiPPV), we did not connect the device directly to the endotracheal tube but to a non-invasive nasobuccal mask (Fig. 1).

The animals were then placed in the lateral decubitus position for the whole duration of the study. The propofol infusion rate was adjusted to obtain a balance between sedation and awakening, and $\mathrm{pCO}_{2}$ values were maintained between 35 and $40 \mathrm{mmHg}$. Propofol was also titrated to control hemodynamic changes, spontaneous motor activity and palpebral reflexes, hypoventilation, and responses to noxious stimuli. Target levels of intoxication were obtained by administering a combination of $940 \mathrm{ppm}(0.94 \%) \mathrm{CO}$ gas, $20 \% \mathrm{O}_{2}$, and $79.906 \% \mathrm{~N}_{2}$ (Pulmo1®, Air Liquide Medical systems@). This was administrated via a secured system using the endotracheal tube during spontaneous breathing. All exhaust gases from the respiratory circuit were scavenged and released outside the building (Fig. 2). The CO concentration in the ambient air was continuously tested $(\mathrm{PAC} 7000 \AA$, Drager $\odot$, Germany).

Catheters were inserted into the carotid or femoral artery to continuously measure blood pressure and to determine $\mathrm{COHb}$ levels (\%). All blood samples were analyzed for $\mathrm{pH}, \mathrm{paCO}_{2}$ ( $\mathrm{mmHg}$ ), $\mathrm{paO}_{2}(\mathrm{mmHg})$, lactate ( $\mathrm{mmol} \mathrm{l}^{-1}$ ), and $\mathrm{COHb}$ using the blood gas analyzer ABL90Flex ${ }^{\circledR}$ (Radiometer ${ }^{\mathrm{TM}}$, Radiometer Medical Aps, Denmark). For each experiment, minute ventilation $\left(\mathrm{ml} \mathrm{min}^{-1}\right)$, invasive blood pressure $(\mathrm{mmHg}), \mathrm{FiO}_{2}(\%)$, heart rate $\left(\mathrm{min}^{-1}\right), \mathrm{SpO}_{2}(\%)$, end-tidal $\mathrm{CO}_{2}(\mathrm{mmHg})$, and temperature $\left({ }^{\circ} \mathrm{C}\right)$ were measured continuously using a pneumotachograph and a Datex-Ohmeda ${ }^{\circledR}$ $\mathrm{S} / 5^{\mathrm{TM}}$ light monitor (Datex-Ohmeda $\odot$, Finland). Table warming was adjusted to maintain a target temperature of $37.5^{\circ} \mathrm{C}$.

Three different devices were investigated and compared to NRM: CPAP Boussignac ${ }^{\circledR}(\mathrm{CPAPb}$, Vygon $\odot$, Ecouen, France) and two PSV devices: Legendair ${ }^{\circledR}$ ventilator (Airox@), France) (PSV-Leg) and Vylife $®($ Vygon $\odot$, Ecouen, France) (PSV-Vy). The CPAPb system provides continuous positive pressure by injecting high-speed gas into a cylinder through angled side channels. This open system is fed by pure oxygen at $25-301 \mathrm{~min}^{-1}$ and delivers $\mathrm{FiO}_{2}$ values from 0.7 to 1.0 , depending on changes in respiratory rate and current volume $[9,10]$. The pressure created from the flow of gas was 


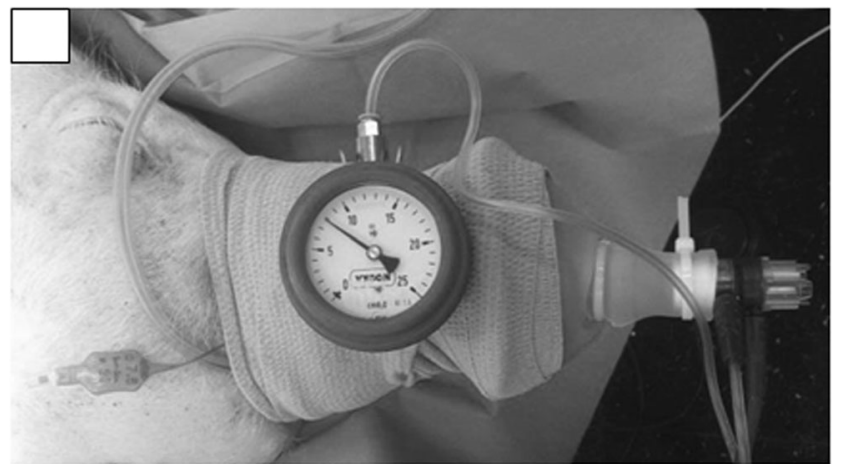

Fig. 1 Experimental ventilation interface. The mask was adapted using an elastic strip to cover their labial commissure and limit air leaks

monitored and maintained at 7.0-7.5 $\mathrm{cm} \mathrm{H}_{2} \mathrm{O}$ [11]. PSV-Vy is an open system, whereas PSV-Leg is a closed system. For both devices, positive airway pressure was set at $+12 \mathrm{~cm}$ $\mathrm{H}_{2} \mathrm{O}$ for the inspiratory phase and $+4 \mathrm{~cm} \mathrm{H}_{2} \mathrm{O}$ for the expiratory phase, with pure oxygen, $\mathrm{FiO}_{2}$, at 1.0.

The complete experimental protocol was composed of four consecutive phases (Fig. 3): (I): the intoxication phase with determination of baseline $\mathrm{COHb}$ blood level followed by iterative sampling every $10 \mathrm{~min}$ until $\mathrm{COHb}$ levels reached $30 \%$ $( \pm 2 \%)$. (II): the "no intervention phase," with disconnection of the CO circuit. During that period, the animals were placed under ambient air (AA) for $10 \mathrm{~min}$. This corresponded to the virtual delay between the extraction of the victim from the toxic environment and the arrival of the first responders in the context of human exposure. This delay was required for the installation of the respiratory device. (III): the treatment phase, with blood samples collected every 6 min until $\mathrm{COHb}$ returned to $5 \%$. (IV): the post-treatment phase without any intervention for $60 \mathrm{~min}$ at $\mathrm{AA}$ in order to document the decrease in $\mathrm{COHb}$ or rule out a rebound.
Each day, one protocol was applied to a single pig, using a randomized treatment that was assigned after the intoxication phase. In order to limit the number of animals required and due to economic constraints, the same animal could be exposed to a new intoxication phase and new randomized treatment using the same protocol the following day.

A minimum time of $12 \mathrm{~h}$ was established between experiments and we determined $\mathrm{COHb}$ levels before each experiment so as to exclude significant residual exposure, and we measured lactate levels so as to exclude end-organ damage.

Overall, four experiments were conducted with ambient air (AA), eight with NRM, five with CPAPb, five with PSV-Leg, and three with PSV-Vy.

The animals were euthanized at the end of the experiments once the study had been completed using a T-61 ${ }^{\circledR}$ (embutramide/mebezonium iodide/tetracaine hydrochloride) injection.

The homogeneity of the intoxication phase was verified by comparing $\mathrm{COHb}$ levels and other parameters between the experimental groups at any time. The $\mathrm{COHb} \mathrm{t}_{1 / 2}$ was assessed

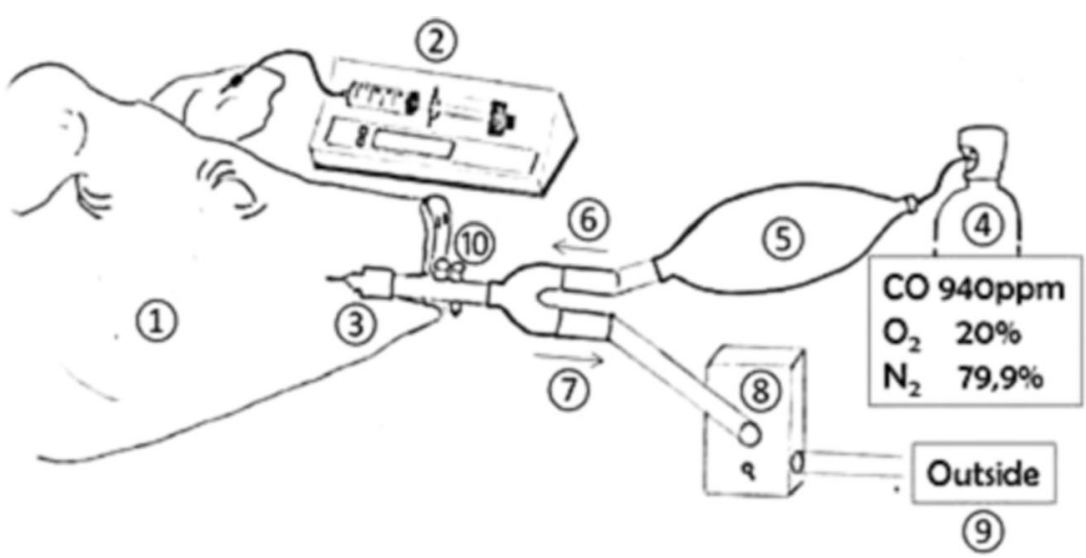

Fig. 2 CO intoxication phase. 1 Pig. 2 Anesthesia with propofol $2 \% .3$ Spontaneous breathing through endotracheal tube. 4 Gas source containing CO 940 ppm. 5 Balloon with gas reserve for inhalation. 6/7 One-direction valve. 8 Exhaled gas scavenger. 9 Gas evacuation outside the room. 10 Pneumotachograph and $\mathrm{FiO}_{2}$ measurement. After the intoxication phase, the endotracheal tube was kept in the same position and was covered by an adapted facial mask connected to the respiratory device (Fig. 1) 


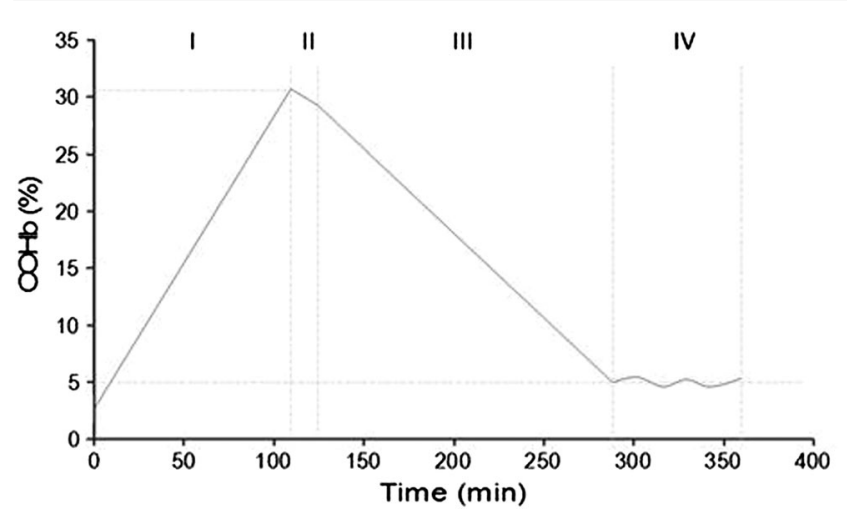

Fig. 3 Experimental protocol. Phase I: intoxication; Phase II: no treatment (atmospheric room air); Phase III: treatment phase with different oxygenation/ventilation devices; Phase IV: no treatment (atmospheric room air) to assess $\mathrm{COHb}$ levels and verify the absence of a rebound

using non-compartmental analysis. The areas under the curve $(\mathrm{AUCs}) \ln (\mathrm{COHB}) \times$ time $(\mathrm{h})$ were calculated. Results were expressed as medians [range], and continuous outcomes were compared using the Kruskal-Wallis test and Dunn's test for multiple comparisons using GraphPad Prism 4® software $(\alpha=0.05)$.

\section{Results}

The clinical parameters were similar during all the phases of the experiment among the different intervention groups (Supplementary table, online resource). There was no significant increase in lactate levels, and no rebounds in $\mathrm{COHb}$ levels were observed up to $1 \mathrm{~h}$ after the treatment had ended.

Measurements for delivered oxygen therapy were the highest in the PSV-Leg group in terms of median $\mathrm{FiO}_{2}$ $(p<0.05$ when compared to NRM, CPAPb, and PSV-Vy), minute ventilation $(p<0.05$ when compared to NRM and $\mathrm{CPAPb})$, and respiratory rate $(p<0.05$ when compared to $\mathrm{NRM}$ and $\mathrm{CPAPb}$ ) (Table 1). Median $\mathrm{pO}_{2}$ values were significantly higher in the PSV-Leg group when compared to the $\mathrm{CPAPb}$ group $(p<0.05)$, and there was no difference in median $\mathrm{pCO}_{2}$ values between the intervention groups (Table 1).

With regard to $\mathrm{COHb}$ toxicokinetics, the median terminal half-life of $\mathrm{COHb}$ was 251, 85, 82, 93, and 58 min for AA, NRM, CPAPb, PSV-Vy, and PSV-Leg, respectively (Fig. 4 and Table 1). All the interventions (NRM, CPAPb, PSV-Vy, and PSV-Leg) were superior to the reference group (AA) in terms of $\mathrm{COHb} \mathrm{t}_{1 / 2}(p<0.001)$. However, there was no statistically significant difference between the intervention groups, with a trend only between PSV-Leg (58 min, $n=5$ ) and NRM (85 $\min , n=8)(p=0.18)$.

The median AUCs for $\ln (\mathrm{COHb}) \times$ time $(\mathrm{h})$ were 170,79 , 83, 100, and 64 for AA, NRM, CPAPb, PSV-Vy, and PSV-
Leg, respectively, with a statistically significant difference only between AA and PSV-Leg $(p=0.002)$.

\section{Discussion}

Our pilot experimental study in swine on $\mathrm{CO}$ intoxication and non-invasive pressure support ventilation with the closed Legendair® system showed promising results in terms of $\mathrm{COHb} \mathrm{t}_{1 / 2}$ and the AUCs for $\mathrm{COHb}$ but did not indicate that there were benefits to using CPAP or PSV-Vy for CO elimination in comparison to NRM.

Non-invasive ventilation modes are widely used to treat acute respiratory failure in pre-hospital settings and emergency units, but, to our knowledge, our study is the first one to evaluate CPAP and PSV specifically in relation to CO intoxication. Several explanations can be hypothesized in light of our results and a few important limitations need to be acknowledged.

Firstly, our results confirm that NRM may not deliver $100 \%$ oxygen and, conversely to $\mathrm{HBO}$, all ventilation supports can only lead to a limited value of $\mathrm{pO} 2$ and a marginal increase in fractional atmospheric pressure [12]. Indeed, the Haldane equation for the reaction of $\mathrm{CO}$ in a blood sample is $[\mathrm{HbCO}] /\left[\mathrm{HbO}_{2}\right]=\mathrm{M} \mathrm{pCO} / \mathrm{pO}_{2}$, where $\left[\mathrm{HbO}_{2}\right]=$ oxyhemoglobin rate, $\mathrm{pCO}=$ partial pressure in $\mathrm{CO}$ dissolved, $\mathrm{pO}_{2}=$ partial pressure in oxygen dissolved, and $\mathrm{M}=$ Haldane constant. Nevertheless, several in vivo studies showed the benefit of the influence of ventilation on $\mathrm{COHb}$ half-life [7]. Improving ventilation without excessive increasing $\mathrm{pO}_{2}$ could limit the adverse effects of hyper-oxygenation. Moreover, our results suggest that ventilation therapies are not equal in terms of CO elimination. Oxygenation using NRM is considered the first standard treatment for $\mathrm{CO}$ poisoning. The $\mathrm{FiO}_{2}$ delivered at $151 \mathrm{~min}^{-1}$ using NRM is expected to reach up to $100 \%$. However, due to unavoidable leaks around the mask and rebreathing, a maximum concentration of $85 \%$ is usually reached $[13,14]$. In our study, the mean $\mathrm{FiO}_{2}$ obtained was $72 \%$. For $\mathrm{CPAPb}$, the mean $\mathrm{FiO}_{2}$ was limited to $58 \%$ for inspiratory flow in our experimental conditions, which runs contrary to the results of Templier et al.'s bench laboratory test [10]. We observed similar results for PSV-Vy, with a mean $\mathrm{FiO}_{2}$ of $51 \%$. Both CPAPb and PSV-Vy are considered open systems. These open-system devices offer the advantage of more comfort for the patient, but the drawback of this is that atmospheric room air is inspired at the same time, thus resulting in lower $\mathrm{FiO}_{2}$ levels in the gas mixture depending on inspiratory flow. Conversely, the PSV-Leg is considered a closed system and delivered higher levels of $\mathrm{FiO}_{2}(92 \%)$ than NRM, CPAPb, and PSV-Vy. Interestingly, the PSV-Leg yielded the best results in terms of $\mathrm{COHb}_{1 / 2}$. Compared to NRM and CPAP, PSV is an effective ventilation mode for partly overcoming the potentially noxious effects of the sedation which decreases MV. It also improves $\mathrm{pO}_{2}$. Nevertheless, 
Table 1 Median [range] respiratory parameters in swine during treatment. $\mathrm{COHb} t_{1 / 2}$ elimination half-life of carboxyhemoglobin, AUC area under the curve, $\mathrm{FiO}_{2}$ fraction of inspired oxygen, $\mathrm{pCO}_{2}$ partial PSV-Leg PSV-Legendair

\begin{tabular}{|c|c|c|c|c|c|c|c|c|c|}
\hline \multirow[b]{2}{*}{$\mathrm{COHb} \mathrm{t}_{1 / 2}(\mathrm{~min})$} & $\mathrm{AA}(n=4)$ & \multicolumn{2}{|c|}{$\operatorname{NRM}(n=8)$} & \multicolumn{2}{|c|}{$\operatorname{CPAP}(n=5)$} & \multicolumn{2}{|c|}{ PSV-Vy $(n=3)$} & \multicolumn{2}{|c|}{ PSV-Leg $(n=5)$} \\
\hline & 251 [130-273] & 85 & [46-116] & 82 & {$[40-94]$} & 93 & [92-113] & 58 & [52-79] \\
\hline $\begin{array}{l}\text { AUC (ln } \mathrm{COHb} \times \text { time } \\
\text { (h)) }\end{array}$ & 170 [126-222] & 79 & {$[57-105]$} & 83 & [55-95] & 100 & [95-102] & 64 & {$[60-65]$} \\
\hline $\mathrm{FiO}_{2}(\%)$ & 21 & 72 & [59-83] & 54 & [49-73] & 51 & [51-53] & 92 & [76-93] \\
\hline $\mathrm{pCO}_{2}(\mathrm{mmHg})$ & $45 \quad[30-58]$ & 43.3 & {$[39.2-52.5]$} & 47.8 & {$[46.5-48.3]$} & 40.6 & {$[37.1-46.7]$} & 44.6 & {$[39.4-48.6]$} \\
\hline $\mathrm{pO}_{2}(\mathrm{mmHg})$ & 88 [49-173] & 369.4 & [230.1-418.2] & 281.0 & [234.0-441.2] & 286.2 & [247.1-300.5] & 475.0 & [323.4-478.6] \\
\hline $\mathrm{MV}\left(\mathrm{ml} \mathrm{min} \operatorname{mon}^{-1}\right)$ & $6090[1800-15,040]$ & 6539 & [5587-10,312] & 7418 & [6788-8460] & 8096 & [6695-8602] & 9726 & {$[9377-11,404]$} \\
\hline
\end{tabular}

pressure of carbon dioxide, $\mathrm{pO}_{2}$ partial pressure of oxygen, $\mathrm{MV}$ minute ventilation in $\mathrm{mL} / \mathrm{min}$. AA atmospheric air, NRM high concentration non-rebreathing mask, CPAPb CPAP Boussignac, PSV-Vy PSV-Vylife,
PSV-Vy and PSV-Leg used the same pressure levels and mode, yet the potential benefit of PSV-Leg mainly seems related to its higher levels of oxygen delivery. In addition, the trigger on PSV-Vy is unchangeable compared to that of PSVLeg, so an inspiratory delay may lead to an increased inspiratory flow and thus decrease $\mathrm{FiO}_{2}$.

Secondly, our study in swine mimicked CO intoxication in humans to a certain extent but differed on several counts. Pigs were selected because they share some physiological cardiorespiratory characteristics with humans [15]. However, the relative affinity of swine hemoglobin for $\mathrm{CO}$ compared to $\mathrm{O}_{2}$ (the Haldane constant $[\mathrm{M}]$ ) at $37{ }^{\circ} \mathrm{C}$ is assumed to be 130 , whereas the median (M) constant in humans is around $218[16,17]$. This lower affinity for CO in swine hemoglobin may result in shorter laboratory experiments. We considered
$30 \% \mathrm{COHb}$ a significant level of intoxication because this level is supposed to induce clinically relevant symptoms in human intoxication and require HBO therapy [4]. The animals in the experiment had a body weight comparable to human (72 to $88 \mathrm{~kg}$ ) and a facial size compatible with CPAP and PSV masks. Nevertheless, we needed to sedate them during the experiment and, as a first pilot experiment had shown numerous obstructive apneic episodes in pigs sedated under propofol, intubation was required. In order to reproduce non-invasive ventilation conditions, we did not directly connect the system to the endotracheal tube but to a nasobuccal mask (Fig. 1).

Thirdly, the power of the statistical analysis was limited by the small number of animals included in each intervention sub-group. This may explain why the difference observed
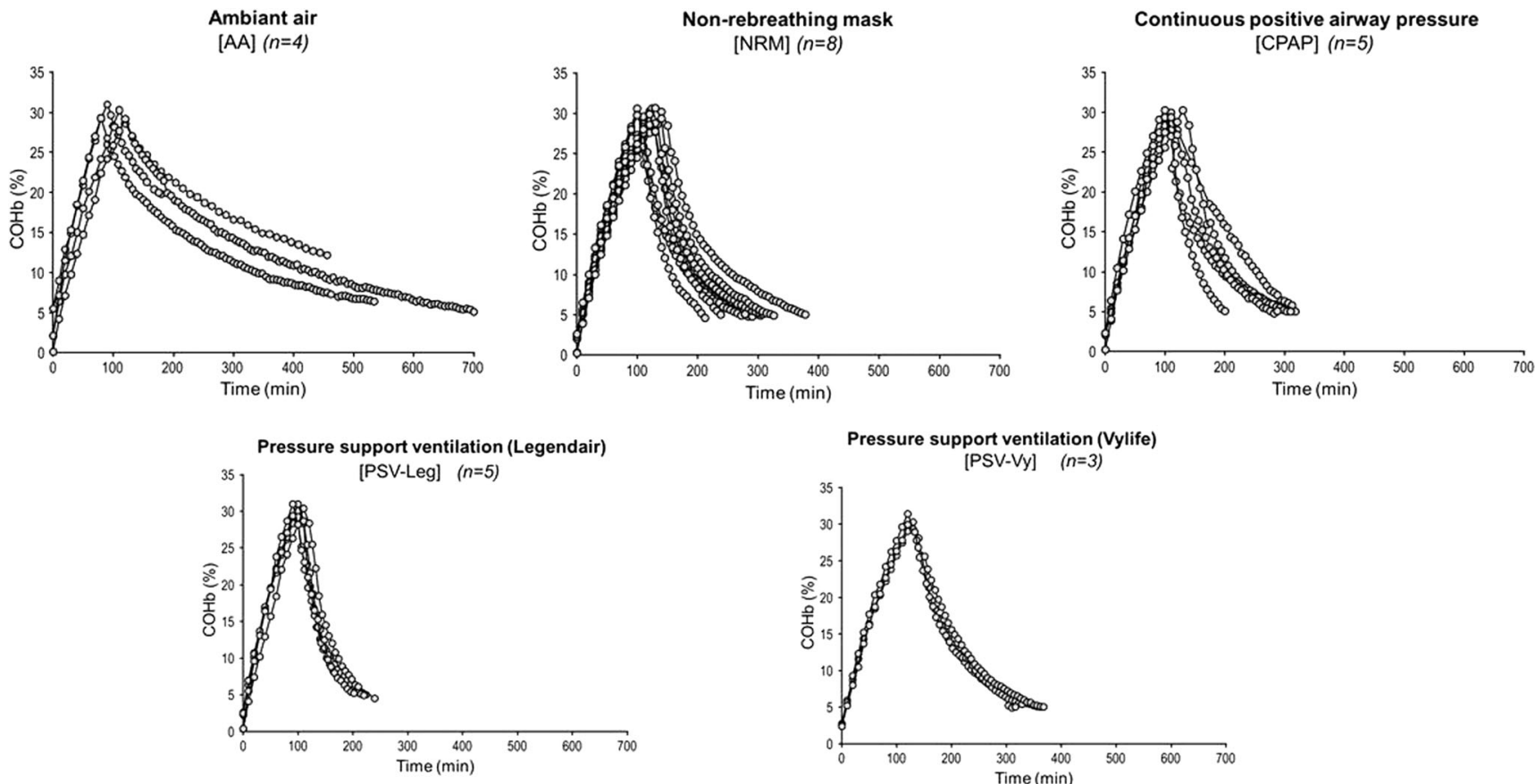

Fig. 4 Toxicokinetic profile of $\mathrm{COHb}$ for each treatment group. Atmospheric air $(n=4), \mathrm{CPAPb}(n=5)$, NRM $(n=8)$, PSV-Leg $(n=5)$, and PSV-Vy $(n=3)$ 
between the PSV-Leg group $(n=5)$ and the NRM group $(n=$ 8 ) was not statistically significant. Moreover, in an exploratory setting, we performed several analyses without considering alpha risk inflation.

Finally, we cannot totally exclude the possibility that prior $\mathrm{CO}$ poisoning could have affected the terminal elimination half-life of $\mathrm{CO}$ in subsequent trials by virtue of end-organ damage. However, another experimental study found that long-term exposure to $200 \mathrm{ppm} \mathrm{CO}>24 \mathrm{~h}$ did not lead to pathological changes in tissues or organs [18]. Moreover, before each experiment, we determined $\mathrm{COHb}$ levels so as to exclude significant residual exposure to $\mathrm{CO}$ and measured lactate levels for every $\mathrm{COHb}$ sample so as to exclude endorgan damage.

\section{Conclusion}

In conclusion, in our study on $\mathrm{CO}$ intoxication in swine, the closed PSV-Leg system gave the shortest $\mathrm{COHb}_{1 / 2}$ (median 58 vs. 85 min with NRM) and the lowest AUC for $\mathrm{COHb}$ (median 63 vs. 79 with NRM). The results of our pilot study suggest that non-invasive ventilation, such as the closed PSVLeg system, can be more efficient than NRM at eliminating $\mathrm{CO}$ when $\mathrm{HBO}$ is unavailable and supports the design of a clinical study to evaluate this hypothesis.

Acknowledgments The authors wish to thank Sabine Jaumotte (Radiometer@, Medical Aps, Denmark) for their essential technical support and the nurses from the emergency unit (Cliniques universitaires Saint-Luc, UCL, Brussels, Belgium) for their assistance and precious help. We thank Doctor Maximilien Thoma for his assistance in surgical procedures and Johanna Maccioni for reviewing the manuscript.

Funding Information This study was supported by the Saint-Luc Foundation and the Experimental Surgery and Transplantation unit (CHEX, Université catholique de Louvain, UCL, Brussels, Belgium).

\section{Compliance with Ethical Standards}

Conflicts of interest ND received financial support from Vygon(C) (France) for this study. Moreover, ND produced pedagogic and promotional medical films for this company. Other authors declare that they have no conflicts of interest.

\section{References}

1. Braubach M, Algoet A, Beaton M, Lauriou S, Heroux ME, Krzyzanowski M. Mortality associated with exposure to carbon monoxide in WHO European member states. Indoor Air. 2013;23(2):115-25. https://doi.org/10.1111/ina.12007.

2. Pace N, Strajman E, Walker EL. Acceleration of carbon monoxide elimination in man by high pressure oxygen. Science. 1950;111(2894):652-4. https://doi.org/10.1126/science.111.2894. 652.
3. Jay GD, McKindley DS. Alterations in pharmacokinetics of carboxyhemoglobin produced by oxygen under pressure. Undersea Hyperb Med J Undersea Hyperb Med Soc Inc. 1997;24:165-73.

4. Buckley NA, Juurlink DN, Isbister G, Bennett MH, Lavonas EJ. Hyperbaric oxygen for carbon monoxide poisoning. Cochrane Database Syst Rev. 2011. https://doi.org/10.1002/14651858. CD002041.pub3.

5. Annane D, Chadda K, Gajdos P, Jars-Guincestre MC, Chevret S, Raphael JC. Hyperbaric oxygen therapy for acute domestic carbon monoxide poisoning: two randomized controlled trials. Intensive Care Med. 2011;37(3):486-92. https://doi.org/10.1007/s00134010-2093-0.

6. Huang CC, Ho CH, Chen YC, Lin HJ, Hsu CC, Wang JJ, et al. Hyperbaric oxygen therapy is associated with lower short- and long-term mortality in patients with carbon monoxide poisoning. Chest. 2017;:S0012-3692(17):30723-7.

7. Fisher JA, Iscoe S, Fedorko L, Duffin J. Rapid elimination of CO through the lungs: coming full circle 100 years on. Exp Physiol. 2011;96(12):1262-9. https://doi.org/10.1113/expphysiol.2011. 059428.

8. Thys F, Roeseler J, Delaere S, Palavecino L, El Gariani A, Marion $\mathrm{E}$, et al. Two-level non-invasive positive pressure ventilation in the initial treatment of acute respiratory failure in an emergency department. Eur J Emerg Med. 1999;6(3):207-14.

9. Spijker EE, de Bont M, Bax M, Sandel M. Practical use, effects and complications of prehospital treatment of acute cardiogenic pulmonary edema using the Boussignac CPAP system. Int J Emerg Med. 2013;6(1):8. https://doi.org/10.1186/1865-1380-6-8.

10. Keenan SP, Sinuff T, Burns KE, Muscedere J, Kutsogiannis J, Mehta S, et al. Clinical practice guidelines for the use of noninvasive positive-pressure ventilation and noninvasive continuous positive airway pressure in the acute care setting. CMAJ. 2011;183(3): E195-214. https://doi.org/10.1503/cmaj.100071.

11. Briganti A, Melanie P, Portela D, Breghi G, Mama K. Continuous positive airway pressure administered via face mask in tranquilized dogs. J Vet Emerg Crit Care (San Antonio). 2010;20(5):503-8. https://doi.org/10.1111/j.1476-4431.2010.00579.x.

12. Wexler HR, Aberman A, Scott AA, Cooper JD. Measurement of intratracheal oxygen concentrations during face mask administration of oxygen: a modification for improved control. Can Anaesth Soc J. 1975;22(4):417-31. https://doi.org/10.1007/BF03004856.

13. Burkhart JE Jr, Stoller JK. Oxygen and aerosolized drug delivery: matching the device to the patient. Cleve Clin J Med. 1998;65(4): 200-8. https://doi.org/10.3949/ccjm.65.4.200.

14. Templier F, Dolveck F, Baer M, Chauvin M, Fletcher D. Laboratory testing measurement of $\mathrm{FIO} 2$ delivered by Boussignac CPAP system with an input of 100\% oxygen. Ann Fr Anesth Reanim. 2003;22(2): 103-7. https://doi.org/10.1016/S0750-7658(02)00859-6.

15. Schomberg DT, Tellez A, Meudt JJ, Brady DA, Dillon KN, Arowolo FK, et al. Miniature swine for preclinical modeling of complexities of human disease for translational scientific discovery and accelerated development of therapies and medical devices. Toxicol Pathol. 2016;44(3):299-314. https://doi.org/10.1177/ 0192623315618292 .

16. Klimisch HJ, Chevalier HJ, Harke HP, Dontenwill W. Uptake of carbon monoxide in blood of miniture pigs and other mammals. Toxicology. 1975;3(3):301-10. https://doi.org/10.1016/0300483X(75)90031-1.

17. Rodkey FL, O'Neal JD, Collison HA. Oxygen and carbon monoxide equilibria of human adult hemoglobin at atmospheric and elevated pressure. Blood. 1969;33(1):57-65.

18. Jones RA, Strickland JA, Stunkard JA, Siegel J. Effects on experimental animals of long-term inhalation exposure to carbon monoxide. Toxicol Appl Pharmacol. 1971;19(1):46-53. https://doi.org/ 10.1016/0041-008X(71)90188-8. 